\title{
Mediating Effect of Depressive Symptoms on the Relationship between Adult Attention Deficit Hyperactivity Disorder and Quality of Life
}

\author{
Ji-Yeong Seo, Cheol-Soon Lee ${ }^{凶}$, Chul-Soo Park, Bong-Jo Kim, Bo-Seok Cha, So-Jin Lee, and In-Young Ahn \\ Department of Psychiatry, Gyeongsang National University Hospital, School of Medicine, Gyeongsang National University, Jinju, Republic of Korea
}

Objective The aim of this study was to investigate whether depressive symptoms affect the relationship between adult attention deficit hyperactivity disorder (ADHD) and the quality of life (QOL) in Korean soldiers.

Methods We evaluated past and present symptoms of adult ADHD (the Korean Adult Attention-Deficit/Hyperactivity Disorder Scale and the Wender Utah Rating Scale), depression (the Center for Epidemiological Studies Depression Scale) and QOL (the Korean version of the SmithKline Beecham 'Quality of Life' scale) in 131 soldiers during mental health screenings performed by a local mental health center. A structured equation model using AMOS 19.0 was used to evaluate the mediating effect of depression.

Results In our first model (without depressive symptoms), adult ADHD significantly affected QOL (standardized regression weight= $-0.51, \mathrm{p}<0.01$ ). After depressive symptoms were added to this model, the direct effect of adult ADHD on QOL was not significant (standardized regression weight $=0.10, \mathrm{p}=0.43$ ). Regarding the indirect effect, adult ADHD significantly affected depression (standardized regression weight $=0.78, \mathrm{p}<0.01$ ), and depression also affected QOL (standardized regression weight $=-0.79, \mathrm{p}<0.01$ ).

Conclusion Through structural equation modeling, the complete mediation model for the influence of depressive symptoms on $\mathrm{ADHD}$ and QOL was confirmed. These findings indicated that it might be important to consider comorbidities, such as depression, when adult $\mathrm{ADHD}$ is being evaluated.

Psychiatry Investig 2014;11(2):131-136

Key Word Adult ADHD and quality of life.

\section{INTRODUCTION}

Attention-Deficit/Hyperactivity Disorder (ADHD) is a disease characterized by attention-deficit, impulsivity and hyperactivity. It is known that $3 \%$ to $7 \%$ of school-age children have ADHD globally. ${ }^{1,2} \mathrm{ADHD}$ is one of the most common neurological conditions in a clinical context. It affects daily, family and social functions, learning ability and cognitive ability. ${ }^{3} \mathrm{ADHD}$ has been seen as a disorder that appears in childhood but improves or disappears when adulthood is reached. However, ADHD symptoms continued into adulthood in $50-65 \%$ of children with ADHD. ${ }^{4}$ The prevalence of ADHD

Received: March 31, 2013 Revised: May 22, 2013

Accepted: May 28, 2013 Available online: April 11, 2014

$\triangle$ Correspondence: Cheol-Soon Lee, MD, PhD

Department of Psychiatry, School of Medicine, Gyeongsang National University, 79 Gangnam-ro, Jinju 660-702, Republic of Korea

Tel: +82-55-750-8872, Fax: +82-55-759-0003, E-mail: psy@gnu.ac.kr

(a) This is an Open Access article distributed under the terms of the Creative Commons Attribution Non-Commercial License (http://creativecommons.org/licenses/bync/3.0) which permits unrestricted non-commercial use, distribution, and reproduction in any medium, provided the original work is properly cited. is estimated at approximately $4 \%$ of the adult population. Some studies have called for proper clinical care for those adults showing ADHD symptoms. ${ }^{5}$

Although the effects of hyperactivity in children with ADHD have been widely discussed in earlier studies, ADHD symptoms in adults have been less studied. Nonetheless, the effects of inattention and impulsivity can be more adverse in adulthood. ${ }^{6}$ It has been reported that adults with ADHD have difficulties carrying out work tasks, dealing with people and complying with social rules, which makes daily functioning difficult. In addition, they may develop drug or alcohol abuse problems and mental illnesses, such as anti-social personality disorder. ${ }^{7}$ The consequences of such symptoms include frequent job changes, part-time jobs and low socioeconomic status. ${ }^{8}$ Adults with ADHD also have a higher rate of separation or divorce (compared to the national average) and experience severe mental conflict and social inadaptability. ${ }^{9}$ As a result, they have low levels of life satisfaction, according to earlier studies. $^{10}$

ADHD in adulthood may result in anti-social personality 
disorder, adjustment disorder and anxiety disorder; however, depression has been described as the most common symptom of ADHD in many studies. ${ }^{11}$ More than $80 \%$ of adult patients with ADHD had at least one mental illness. One-third of these patients suffer from at least three different mental disorders. ${ }^{12}$ The likelihood of developing depression is five times greater in adults with ADHD compared to adults without ADHD. Adults with ADHD also experience an earlier onset of depression, increased morbidity, more severe symptoms and a higher suicide rate compared to adults without ADHD. ${ }^{13}$ Compared with the control group, the ADHD group with depression exhibited more difficulties at school or the workplace and lower treatment response rates, which implies the need for both drug and mental therapy. ${ }^{14}$ As ADHD is accompanied by a high prevalence of other mental conditions, the possibility of misdiagnosing adults with ADHD is high, which in turn makes diagnosis and treatment more difficult. ${ }^{15}$ When adults with ADHD fail to receive the appropriate treatment, they experience continuous problems with daily functioning, and their quality of life (QOL) declines as a result.

Previous studies have mainly addressed the behavioral disorders associated with ADHD in adults and examined the observable effects of drug treatment on thesebehaviors. ${ }^{16}$ Local studies of ADHD in adults have been insufficient because of the lack of reliable diagnostic criteria and assessment tools. In particular, studies investigating the effects of comorbidities on QOL are rare. This study was aimed to investigate the relationship between ADHD symptoms, depressive symptoms and QOL in soldiers who perform similar tasks in the same environment. At the same time, the effects of depressive symptoms on the relationship between $\mathrm{ADHD}$ and QOL were also analyzed.

\section{METHODS}

\section{Subjects}

Members of the regional mental clinic center were dispatched to an army base in a remote area and distributed questionnaires to 131 soldiers. The self-administered questionnaire consisted of items describing past and present ADHD symptoms, depression and QOL. The subjects were informed of the purpose of the study and told that the study data would be aggregated. All subjects signed consent agreements. The agreements and completed questionnaires were collected and sent to the regional mental clinic center. Questionnaires with missing responses were excluded from the analysis. Research protocols and the study process were approved by the Clinical Medical Research Ethics Committee of the Gyeongsang National University Hospital.

\section{Assessment instruments}

\section{Korean Adult Attention-Deficit/Hyperactivity Disorder Scale}

K-AADHDS is a translated version of the DSM-IV Adult Attention-Deficit/Hyperactivity Disorder Scale, which was developed by Murphy and Barkley. This scale is widely used for epidemiological studies in the local context. This self-administered instrument includes 18 DSM-IV ADHD items and consists of nine items measuring attention-deficit and nine items measuring impulsivity and hyperactivity. The frequency of ADHD symptoms experienced over the last six months was measured on a four-point scale (ranging from "almost never" to "very often"). The reliability and validity of the instrument were verified in a study involving 553 college students. ${ }^{17}$

\section{Korean-Wender Utah Rating Scale}

The Korean-Wender Utah Rating Scale (K-WURS) is a translated version of the 25-item instrument designed to diagnose ADHD in adults, which was developed by Wender in 1993. This self-administered questionnaire uses a five-point scale with 0 being "not at all" and 4 being "extremely". The scale results in a score ranging from 0 to 100 and a cutoff point of 46 and above; it is used to diagnose adult ADHD in the U.S. Although its reliability and validity have not yet been verified, this instrument has been employed in several South Korean studies to measure childhood ADHD symptoms in adults with ADHD. $^{18}$

\section{Center for Epidemiological Studies Depression scale}

The Center for Epidemiological Studies Depression scale (CES-D) is also a self-administered instrument comprised of 20 items that are used to measure depression, feelings of futility andguilt, helplessness, retarded psychomotor function, desperation and sleep disorder. Each item is designed to measure symptoms that have been experienced in the previous week, making the instrument suitable for epidemiological studies. The CES-D is commonly used to compare the prevalence of depression in terms of nation, population, age and sex. This scale was translated by Cho et al. ${ }^{19}$ for use in South Korea. A cut-off score of 24/25 is used to diagnose depression, and a score of 20/21 is used for epidemiological purposes.

\section{Korean version of the SmithKline Beecham 'Quality of Life' Scale}

The SBQOL, developed by Dunbar in 1992, was translated for use in Korea by Yoon et al..$^{20}$ The K-SBQOL is comprised of 23 items that are grouped into eight sub-scales: psychological and physical well-being, feeling, social relationship, internalexternal control, work and job, financial status, activities and 
interest. The score on each item ranges from 1 to 10. Twelve items were reverse scored, and the total scores ranged from 23 to 230 . This tool categorizes different mental statuses in three elements ('current self', 'ideal self' and 'sick self') and helps respondents assess their view of the world from the perspective of the different health statuses. This scale yields the QOL score of each element and can also determine inter-element distances. As this tool can be used repeatedly for measurements, it is possible to assess QOL changes over time, making it useful for many studies. Five elements were identified in a study conducted with 377 college students, including competence, psychological well-being, stability, physical well-being and vitality. This study confirmed its reliability and validity.

\section{Statistical analysis of data}

The collected data were statically analyzed to define the socio-demographic characteristics of the subjects and compute the mean score of items. Pearson's correlation analysis was used to define the strength of the association between ADHD symptoms and QOL and depression and QOL. A path analysis was also performed to measure the relationship between past and present ADHD symptoms and QOL and the mediated effects of depression on ADHD symptoms and QOL. A statistical analysis was performed using SPSS for Windows, version 12.0 (SPSS Inc., Chicago, IL, USA) and AMOS 19.0 (SPSS Inc., Chicago, IL, USA). P-values $<0.05$ were considered statistically significant.

\section{RESULTS}

The socio-demographic characteristics of the subjects are described in Table 1. Pearson's correlation analysis of the KAADHDS, K-WURS, CES-D and K-SBQOL scores revealed statistically significant correlations among all the items $(\mathrm{p}<$ 0.01 ) (Table 2). Structural equation modeling was performed to analyze the relationship between ADHD symptoms and QOL in the first model and the relationship between ADHD symptoms, QOL and depressive symptoms in the second model. The model fit indices were NFI $=0.95, \mathrm{IFI}=0.97, \mathrm{TLI}=0.96$, $\mathrm{CFI}=0.97$ and RMSEA $=0.08$. Without depressive symptoms, a negative correlation was observed between adult ADHD symptoms and QOL (standardized regression weight $=-0.51$, $\mathrm{p}<0.01$ ) (Figure 1A). When depressive symptoms was included in the model, the direct effects of past and present ADHD symptoms on QOL were not significant (standardized regression weight $=0.10, \mathrm{p}=0.44$ ). However, $\mathrm{ADHD}$ symptoms significantly affected depression (standardized regression weight $=0.78, \mathrm{p}<0.01$ ). As for the total effects, the ADHD symptoms exhibited indirect effects on QOL through depression as a mediator (Figure 1B). Specifically, in the both model,
Table 1. Demographic characteristics and means of K-AADHDS, K-WURS, CES-D and K-SBQOL

\begin{tabular}{lc}
\hline & $\mathrm{N}(\%)$ or mean \pm SD \\
\hline Age (years) & $20.85 \pm 1.21$ \\
Education & $20(15.3)$ \\
High school graduate & $107(81.7)$ \\
Grade of universities & $2(1.5)$ \\
Above college graduate & $2(1.5)$ \\
Others & \\
Religion & $56(42.7)$ \\
No religion & $41(31.3)$ \\
Christian & $29(22.1)$ \\
Buddhism & $6(3.9)$ \\
Others & \\
Rank & $35(26.7)$ \\
Private & $45(34.4)$ \\
Private first-class & $38(29.0)$ \\
Corporal & $9(6.9)$ \\
Sergeant & $4(3.1)$ \\
Others & $5.49 \pm 5.56$ \\
K-AADHDS & $9.89 \pm 10.11$ \\
K-WURS & $5.94 \pm 5.83$ \\
CES-D & $180.60 \pm 32.33$ \\
K-SBQOL &
\end{tabular}

K-AADHDRS: Korean Adult Attention Deficit/Hyperactivity Scale, K-WURS: Korean-Wender Utah rating scale, CES-D: Center for epidemiological studies depression scale, K-SBQOL: Korean version of the SmithKline Beecham quality of life's scale, SD: standard deviation

Table 2. Pearson's correlation analysis of ADHD symptoms, depressive symptoms and QOL

\begin{tabular}{lccc}
\hline & K-AADHDRS & K-WURS & CES-D \\
\hline K-AADHDRS & 1 & & \\
K-WURS & $0.71^{*}$ & 1 & \\
CES-D & $0.69^{*}$ & $0.63^{*}$ & 1 \\
K-SBQOL & $-0.42^{*}$ & $-0.39^{*}$ & $-0.67^{*}$ \\
\hline
\end{tabular}

${ }^{*} \mathrm{p}<0.01$. K-AADHDRS: Korean Adult Attention Deficit/Hyperactivity Scale, K-WURS: Korean-Wender Utah rating scale, CES-D: Center for Epidemiological Studies Depression scale, K-SBQOL: Korean version of the SmithKline Beecham 'Quality of Life' scale

past ADHD symptoms show more influence on latent variable, adult ADHD. The results of the structural equation modeling confirmed that depression served as a complete mediator of the relationship between ADHD symptoms in adults and QOL.

\section{DISCUSSION}

This study aimed to investigate the relationship between 


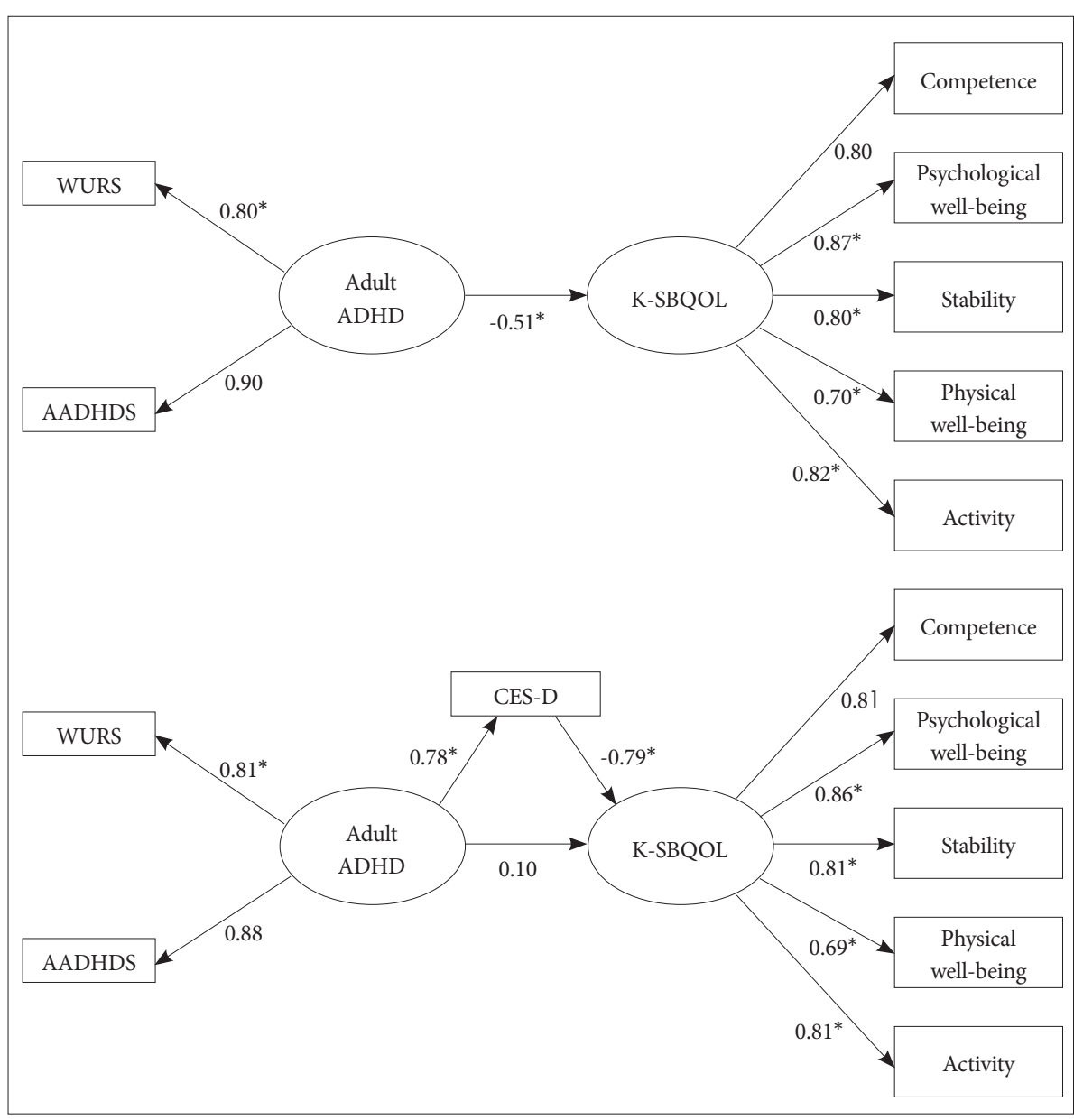

Figure 1. Structural equation model of the relationship between ADHD symptoms, depressive symptoms and QOL. ${ }^{*} p<0.01$. K-AADHDRS: Korean Adult Attention Deficit/Hyperactivity Scale, K-WURS: Korean-Wender Utah rating scale, CES-D: Center for Epidemiological Studies Depression scale, K-SBQOL: Korean version of the SmithKline Beecham 'Quality of Life' scale.
ADHD symptoms, depressive symptoms and QOL and the effects of depressive symptoms on the relationship between ADHD symptoms and QOL. A negative correlation was observed between past and present ADHD symptoms in adults and their QOL. Depressive symptoms also played a complete mediator role in the relationship between ADHD symptoms and QOL in adults with ADHD.

Previous studies have suggested that the likelihood of developing depression is high in adults with ADHD. ${ }^{8,21}$ When ADHD was accompanied by depression, the patients were afflicted with worsened conditions, which subsequently impinged on their QOL. ${ }^{22}$ The results of this study are consistent with previous studies that determined ADHD symptoms significantly increased the severity of depression.

Adults with ADHD have many ADHD-specific outcomes, including learning and occupational difficulties and family and social functioning disorders. When comorbid conditions were present, the adverse effects increased in terms of QOL. ${ }^{23}$ In a study investigating the relationship between $\mathrm{ADHD}$ symptoms, QOL, depression and anxiety, the ADHD group exhibited higher levels of depression and anxiety and lower QOL compared to the control group. ${ }^{24}$ Previous studies have fo- cused on the effects of ADHD and comorbidities on QOL, but the present study investigated the association between depression and $\mathrm{ADHD}$ symptoms. By identifying a direct mediator role for depression, this study distinguishes its findings from other studies.

According to studies published abroad, when ADHD is accompanied by comorbidities, ADHD exhibits variations in symptom expression, which makes it more difficult to treat ADHD and eventually leads to longer treatment durations and greater costs. Moreover, daily functioning (e.g., learning and occupational difficulties) deteriorated, and the risk of suicide increased. ${ }^{25}$ The reported consequences of ADHD and its comorbidities included unwanted pregnancy and the risk of sexually transmitted diseases resulting from impulsive sexual relationships, reduced income, increased domestic problems (e.g., divorce) and continued unemployment. QOL was threatened as a result. ${ }^{26}$ A local study of 6081 soldiers suggested the importance of the accurate assessment of the comorbidities accompanying ADHD. In that study, the ADHD group demonstrated an increase in alcohol and nicotine dependence, depression, anxiety disorders, obsessive-compulsive disorder, social phobia, sleep disorders and the risk of suicide. ${ }^{27}$ 
When comorbidities are present in adults with $\mathrm{ADHD}, \mathrm{AD}-$ $\mathrm{HD}$ becomes more difficult to diagnose, as the symptom expression varies. Consequently, ADHD is not treated properly, despite deteriorating QOL. ${ }^{28}$ When adults with ADHD had low self-esteem, depression, oversensitivity, impulsivity, affective instability and uncontrolled anger, these symptoms could be misdiagnosed as borderline personality disorder or bipolar disorder. In those circumstances, ADHD treatment becomes uncertain. ${ }^{29}$ Untreated ADHD will continue to impair daily functioning and will eventually impact QOL, resulting in a decline in production and additional health care costs in a social context. ${ }^{30}$ Despite the afflictive manifestations of $\mathrm{AD}$ $\mathrm{HD}$ in adults, studies investigating the effects of comorbid conditions on QOL have been rare in South Korea. Over the last decade, $294 \mathrm{ADHD}$ studies have been published. Of those studies, $16.7 \%$ addressed ADHD in adults, and none of these studies discussed the QOL of patients and the interrelationship between ADHD and QOL. ${ }^{31}$ In contrast, many foreign studies have already begun to address the issue of ADHD and comorbidities in adults as a source of serious family and social problems. Various assessment instruments have been developed with the aim of measuring the QOL of patients with ADHD. ${ }^{32}$ There is another scale about quality of life of Adult ADHD (AAQoL) even though it doesn't have validity in South Korea. The items of the AAQoL were generated based on data collected from clinical experts, patients, and published literature indicating that adult ADHD has an impact on functioning in five areas: work, daily activities, relationships, psychological well-being and physical well-being. ${ }^{33}$ Even though we also found effects on various subsets of QOL in this study, there is need to evaluate QOL using the disease specific QOL scale with various subsets. Therefore, it is imperative for researchers to develop evaluation methods for its comorbidities and assessment tools for QOL by considering the problems caused by ADHD.

The present study does have limitations. Firstly, as the data on previous ADHD symptoms in subjects were collected at a single point in time in a cross-sectional survey, the changes in variables over time and the association between $\mathrm{ADHD}$ symptoms and depression cannot be clearly explained. Secondly, using self-administered questionnaires may undermine the objectivity expected in symptom assessment, which might result in response shift and recall bias. Thirdly, given that the subjects were all soldiers in their 20s, generalizing the results of this study to any larger group is not justified. Forthly, we didn't consider other comorbidities such as addiction, anxiety disorders, other mood disorders which usually accompanied with adult $\mathrm{ADHD}$ and might affect on results of this study.

To establish standardized diagnostic criteria for ADHD, a questionnaire-based approach must be accompanied by ob- servation and structured clinical interviews. The study subjects must be composed of people from different population groups, and there must be a tracking mechanism to follow children with ADHD into adulthood for a prospective analysis on depression and QOL. Any future study that overcomes the above mentioned limitations will provide useful information that can be used for ADHD and psychological treatments for adults with reduced QOL because of ADHD and its comorbidities. Given the high prevalence of comorbidities, such as depression, in adults with $\mathrm{ADHD}$, it is crucial to develop assessment tools that are designed to accurately assess these comorbidities and QOL under local circumstances.

\section{REFERENCES}

1. Cantwell DP. Attention deficit disorder: a review of the past 10 years. J Am Acad Child Adolesc Psychiatry 1996;35:978-987.

2. Bird HR, Canino G, Rubio-Stipec M, Gould MS, Ribera J, Sesman M, et al. Estimnates of the prevalence of childhood maladjustment in a community survey in Puerto Rico: The use of combined measures. Arch Gen Psychiatry 1988;45:1120-1126.

3. DuPaul GJ, McGoey KE, Eckert TL VanBrakle J. Preschool children with attention-deficit/hyperactivity disorder: impairments in behavioral, social, and school functioning. J Am Acad Child Adolesc Psychiatry 2001;40:508-515.

4. Mannuzza S, Klein RG, Bessler A, Malloy P, LaPadula M. Adult psychiatric status of hyperactive boys grown up. Am J Psychiatry 1998;155: 493-498.

5. Kessler RC, Adler L, Barkley R, Biederman J, Conners CK, Demler O, et al. The prevalence and correlates of adult ADHD in the United States: results from the National Comorbidity Survey Replication. Am J Psychiatry 2006;163:716-723.

6. Murphy K, Barkley RA. Attention deficit hyperactivity disorder adults: comorbidities and adaptive impairments. Compr Psychiatry 1996;37: 393-401.

7. Adler LA. Clinical presentations of adult patients with ADHD. J Clin Psychiatry 2004;65(suppl 3):8-11.

8. Able SL, Johnston JA, Adler LA, Swindle RW. Functional and psychosocial impairment in adults with undiagnosed ADHD. Psychol Med 2007;37:97-107.

9. Barkley RA, Murphy K, Kwasnik D. Psychological adjustment and adaptive impairments in young adults with ADHD. J Atten Disord 1996; 1:41-54.

10. Agarwal R, Goldenberg M, Perry R, Ishak WW. The quality of life of adults with attention deficit hyperactivity disorder: a systematic review. Innov Clin Neurosci 2012;9:10-21.

11. Sobanski E. Psychiatric comorbidity in adults with attention-deficit/ hyperactivity disorder (ADHD). Eur Arch Psychiatry Clin Neurosci 2006;256(suppl 1):i26-i31.

12. Barkley RA, Murphy KR, Fischer M. ADHD in Adults: What the Science Says. New York: Guilford Press; 2010.

13. Biederman J, Ball SW, Monuteaux MC, Mick E, Spencer TJ, McCREARY M, et al. New insights into the comorbidity between ADHD and major depression in adolescent and young adult females. J Am Acad Child Adolesc Psychiatry 2008;47:426-434.

14. Fischer AG, Bau CH, Grevet EH, Salgado CA, Victor MM, Kalil KL, et al. The role of comorbid major depressive disorder in the clinical presentation of adult ADHD. J Psychiatr Res 2007;41:991-996.

15. Mannuzza S, Klein RG, Bessler A, Malloy P, LaPadula M. Adult outcome of hyperactive boys. Educational achievement, occupational rank, and psychiatric status. Arch Gen Psychiatry 1993;50:565-576. 
16. Wender PH. Pharmacotherapy of attention-deficit/hyperactivity disorder in adults. J Clin Psychiatry 1998;59(Suppl 7):76-79.

17. Kim EJ. The validation of Korean ADHD scale. Korean J Clin Psychol 2003;22:897-911.

18. Lee KS, Ahn JS, Shin JH. Attention-deficit hyperactivity symptoms in childhood of adult bipolar disorder/schizophrenia patients. J Child Adolesc Psychiatry 1998;9:26-33.

19. Cho MJ, Kim KH. Diagnostic validity of the CES-D (Korean version) in the assessment of DSM-III-R major depression. J Korean Neuropsychiatr Assoc 1993;32:381-399.

20. Yoon JS, Kook SH, Lee MS. A preliminary study on Korean version of the SmithKline Beecham Quality of Life Scale (KvSBQOL). J Korean Neuropsychiatr Assoc 1998;37:280-294.

21. Torgersen T, Gjervan B, Rasmussen K. ADHD in adults: a study of clinical characteristics, impairment and comorbidity. Nord J Psychiatry 2006;60:38-43.

22. McIntosh D, Kutcher S, Binder C, Levitt A, Fallu A, Rosenbluth M. Adult ADHD and comorbid depression: A consensus-derived diagnostic algorithm for ADHD. Neuropsychiatr Dis Treat 2009;5:137-150.

23. Goodman DW. The consequences of attention-deficit/hyperactivity disorder in adults. J Psychiatr Pract 2007;13:318-327.

24. Chao CY, Gau SS, Mao WC, Shyu JF, Chen YC, Yeh CB. Relationship of attention-deficit-hyperactivity disorder symptoms, depressive/anxiety symptoms, and life quality in young men. Psychiatry Clin Neurosci 2008; 62:421-426.

25. McGough JJ, Smalley SL, McCracken JT, Yang M, Del'Homme M, Lynn $\mathrm{DE}$, et al. Psychiatric comorbidity in adult attention deficit hyperactivity disorder: findings from multiplex families. Am J Psychiatry 2005;
162:1621-1627.

26. Klassen LJ, Katzman MA, Chokka P. Adult ADHD and its comorbidities, with a focus on bipolar disorder. J Affect Disord 2010;124:1-8.

27. Park S, Cho MJ, Chang SM, Jeon HJ, Cho SJ, Kim BS, et al. Prevalence, correlates, and comorbidities of adult ADHD symptoms in Korea: Results of the Korean epidemiologic catchment area study. Psychiatry Res 2011;186:378-383.

28. McGough JJ, Barkley RA. Diagnostic controversies in adult attention deficit hyperactivity disorder. Am J Psychiatry 2004;161:1948-1956.

29. Kooij SJJ, Bejerot S, Blackwell A, Caci H, Casas-Brugué M, Carpentier $\mathrm{PJ}$, et al. European consensus statement on diagnosis and treatment of adult ADHD: The European Network Adult ADHD. BMC Psychiatry 2010;10:67.

30. Birnbaum HG, Kessler RC, Lowe SW, Secnik K, Greenberg PE, Leong SA, et al. Costs of attention deficit-hyperactivity disorder (ADHD) in the US: excess costs of persons with ADHD and their family members in 2000. Curr Med Res Opin 2005;21:195-205.

31. Kim DI, Kim IN, Jung SR, Kim EH, Kim HJ, Lee YR, et al. Current status on studies of ADHD in Korea: Synthesis of research from 1999 to 2008. Korea J Learn Disabil 2009;6:101-127.

32. Rösler M, Retz W, Thome J, Schneider M, Stieglitz RD, Falkai P. Psychopathological rating scales for diagnostic use in adults with attention-deficit/hyperactivity disorder (ADHD). Eur Arch Psychiatry Clin Neurosci 2006;256(Suppl 1):i3-i11.

33. Brod M, Perwien A, Adler L, Spencer T, Johnston J. Conceptualization and assessment of Quality of Life for adults with Attention-Deficit/Hyperactivity Disorder. Prim Psychiatry 2005;12:58-64. 